\title{
Penerapan Multimedia TAVAGIS Berbasis Prezi dalam Pembelajaran Kurikulum 2013 bagi Guru Sekolah Dasar di Kabupaten Kuningan
}

\author{
Agatha Kristi Pramudika Sari ${ }^{1}$, Dyah Puteria Wati² \\ 1, 2 STKIP Muhammadiyah Kuningan
}

\begin{tabular}{l} 
Article History \\
\hline Received 01.08.2019 \\
Received in revised form \\
10.09 .2019 \\
Accepted 05.10 .2019 \\
Available online 28.10 .2019
\end{tabular}

\begin{abstract}
APPLICATION OF PREZI-BASED TAVAGIS MULTIMEDIA IN LEARNING CURRICULUM 2013 FOR ELEMENTARY SCHOOL TEACHERS IN KUNINGAN REGENCY. The curriculum currently being implemented in elementary schools in Indonesia is the 2013 curriculum. One of the problems faced regarding the implementation of the 2013 curriculum is the lack of mastery of information and technology (IT) by teachers, due to learning habit patterns that still do not consider IT's role in improving quality learning. Though teachers are required to master IT in this technological era. This community service activity is intended for fourth grade teachers in elementary schools in Kuningan District, Kuningan Regency. The purpose of this training is to improve the skills of teachers in the IT field, in making and implementing Prezi-based TAVAGIS Multimedia in 2013 elementary school curriculum learning. The method of implementing this activity consists of several stages, namely: 1) Planning which includes partner surveys, training licenses, preparation of training modules, training preparation and coordination, and program socialization, 2) Implementation of PKM activities which include training on Prezi-based TAVAGIS multimedia development and use assistance multimedia that has been made, 3) Evaluation and follow-up. Based on the results of observations and quisioner, training in making and assisting the implementation of Prezi-based TAVAGIS multimedia runs smoothly and some obstacles that arise can be resolved so that this activity can improve the knowledge and skills of making Prezi-based TAVAGIS multimedia, thus helping teachers to create interactive, interesting, and fun learning.
\end{abstract}

KEYWORDS: Curriculum 2013, Elementary School, Multimedia, Prezi, TAVAGIS.

DOI: $10.30653 / 002.201943 .185$

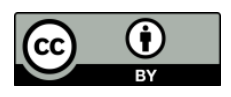

This is an open access article distributed under the terms of the Creative Commons Attribution 4.0 International License, which permits unrestricted use, distribution, and reproduction in any medium, provided the original work is properly cited. (c) 2019 Agatha Kristi Pramudika Sari, Dyah Puteria Wati.

\section{PENDAHULUAN}

Guru dalam pembelajaran di era yang serba digital harus mempunyai usaha untuk meningkatkan keterampilan diri dalam memanfaatkan IT sebagai media pembelajaran.

\footnotetext{
${ }^{1}$ Corresponding author: STKIP Muhammadiyah Kuningan; Jl. Syeh Maulana Akbar, Kuningan, Kec. Kuningan, Kabupaten Kuningan, Jawa Barat 45511; Email: pramudikasari90@gmail.com
} 
Hal tersebut bertujuan agar kurikulum dapat tersampaikan dengan optimal kepada siswa, sehingga bisa menghasilkan output yang baik. Kurikulum yang sedang dilaksanakan di sekolah dasar saat ini di Indonesia adalah kurikulum 2013. Kurikulum 2013 sudah dilaksanakan secara terbatas di beberapa sekolah. Guru dan kepala sekolah sudah dibekali melalui pendidikan dan pelatihan implementasi kurikulum 2013 sekaligus telah disediakan pula buku-bukunya.

Identifikasi masalah yang dihadapi mengenai implementasi kurikulum 2013 adalah minimnya penguasaan informasi dan teknologi (IT) oleh guru, dikarenakan pola kebiasaan pembelajaran yang masih belum menganggap penting peranan IT dalam meningkatkan kualitas pembelajaran. Padahal guru dituntut untuk menguasai IT di era teknologi ini. Mayoritas guru merasa sudah puas akan materi yang telah disampaikan dengan metode ceramah tanpa IT, walaupun sarana dan infrastruktur sudah mendukung untuk diterapkan IT di sekolah-sekolah tersebut. Kepercayaan diri guru yang kurang dalam menggunakan IT dalam proses pembelajaran juga menjadi kendala pembelajaran kurikulum 2013. Guru takut gagal mengajar melalui penggunaan IT yang saat ini sangat disarankan.

Perkembangan IT telah membawa pengaruh besar dalam proses pembelajaran sekalipun di sekolah dasar. Tersedianya fasilitas komputer dan internet di sekolah maupun di rumah memungkinkan peserta didik untuk belajar kapan dan di mana saja dengan lingkup yang sangat luas karena semua informasi yang kita inginkan dapat kita peroleh dengan mengakses internet. Namun, apabila peserta didik usia sekolah dasar tidak didampingi dan diarahkan pada kegiatan positif ketika memanfaatkan komputer, smartphone, dan internet, maka dikhawatirkan IT yang berkembang justru akan merusak generasi bangsa. Berdasarkan peneliyian yang dilakukan oleh Sari dan Falah (2018) menyatakan bahwa tingkat stres level siswa pada fullday school lebih tinggi dari pada half day school. Maka multimedia TAVAGIS berbasis Prezi juga dapat digunakan sebagai alternatif untuk mengurangi stress level siswa, khususnya di sekolah dasar.

Untuk memperbaiki mutu pembelajaran khususnya kurikulum 2013 di sekolah dasar, guru harus bisa mengoptimalkan diri untuk memanfaatkan fasilitas IT yang telah tersedia di sekolah sebagai multimedia pembelajaran dalam menyampaikan materi pembelajaran. Hal tersebut sejalan dengan Rumijdan et al (2017) bahwa keterampilan pengembangan desain dan pembuatan media pembelajaran yang dimiliki guru akan menghasilkan benda yang dapat digunakan sebagai media pembelajaran yang dapat memungkinkan murid menjadi aktif, kreatif, dan menyenangkan dalam kegiatan belajarnya. Salah satu upaya peningkatan keterampilan membuat media berbasis IT yang dapat diikuti guru sekolah dasar untuk menunjang pembelajaran kurikulum 2013 adalah Pelatihan Pembuatan dan Pendampingan Penerapan Multimedia TAVAGIS (Text, Audio, Video, Animasi, Graph, Interactivity, and Special Effects) Berbasis Prezi dalam Pembelajaran Kurikulum 2013. UPTD Pendidikan yang dijadikan mitra dalam program kemitraan masyarakat ini adalah UPTD Pendidikan Kecamatan Kuningan yang menaungi 52 sekolah baik swasta maupun negeri.

Multimedia pembelajaran berguna untuk menyalurkan pesan (pengetahuan, keterampilan, dan sikap) serta dapat merangsang pilihan, perasaan, perhatian, dan kemauan siswa sehingga secara sengaja proses belajar, bertujuan, dan terkendali (Daryanto, 2011:49). Menurut Kustiono (2010:1) kata "multimedia" dapat diartikan sebagai perpaduan harmonis antara berbagai media baik teks (regular maupun hypertext), 
gambar, grafik, audio, video/film, dan animasi, yang dikemas secara sinergis untuk mencapai tujuan (pembelajaran) tertentu.

Aplikasi Prezi merupakan salah satu program yang dapat digunakan untuk membuat multimedia TAVAGIS (Teks, Audio, Video, Animasi, Graph, Interacivity, and Spesial Effect) yang menarik untuk pembelajaran. Prezi adalah sebuah perangkat lunak untuk presentasi berbasis internet (SaaS). Selain untuk presentasi, Prezi juga dapat digunakan sebagai alat untuk mengeksplorasi dan berbagi ide di atas kanvas virtual. Prezi menjadi unggul karena program ini menggunakan Zooming User Interface (ZUI), yang memungkinkan pengguna Prezi untuk memperbesar dan memperkecil tampilan media presentasi yang dibuat. Prezi digunakan sebagai alat untuk membuat presentasi dalam bentuk linier maupun non-linier, yaitu presentasi terstruktur sebagai contoh dari presentasi linier, atau presentasi berbentuk peta-pikiran (mindmap) sebagai contoh dari presentasi non-linier. Program ini dibuat melalui komputer dan dapat diakses pada smartphone berbasis android (Rusyfian, 2016, p. 2).

Tujuan dari program ini adalah untuk meningkatkan keterampilan guru pada bidang IT, dalam membuat dan menerapkan Multimedia TAVAGIS berbasis Prezi dalam pembelajaran kurikulum 2013 sekolah dasar. Multimedia pembelajaran yang telah dibuat berbasis Prezi, diharapkan dapat membantu guru dalam menyampaikan materi secara berkualitas, menarik, dan optimal, sehingga pembelajaran kurikulum 2013 lebih bermakna dan dapat membantu siswa agar mencapai standar akademik serta mengembangkan potensinya. Harapan tersebut didukung dengan penelitian yang dilakukan Fatmawati (2016) yang menyatakan bahwa media Prezi berpengaruh positif terhadap motivasi belajar siswa serta didukung oleh penelitian yang dilakukan oleh Suryani, et al (2015) bahwa penggunaan media Prezi dapat meningkatkan kreativitas peserta didik. Maka dari itu, untuk menyusun multimedia berbasis IT yang menarik, efektif, dan fleksibel perlu adanya pelatihan khusus disertai dengan pendampingan penerapannya sehingga dapat memperbaiki proses pembelajaran dengan maksimal (Wati, 2018).

\section{METODE PELAKSANAAN}

Metode pelaksanaan kegiatan menjelaskan tahapan atau langkah-langkah dalam melaksanakan pelatihan pembuatan dan pendampingan penerapan multimedia TAVAGIS (Teks, Audio, Video, Animasi, Graph, Interacivity, and Spesial Effect) berbasis Prezi dalam pembelajaran Kurikulum 2013 bagi guru Sekolah Dasar di Kabupaten Kuningan. Langkah-langkah dari pelaksanaan PKM ini adalah sebagai berikut.

\section{Perencanaan}

\section{Survei Mitra}

Survei mitra bertujuan untuk menganalisis situasi dan keadaan mitra yang direncanakan sebagai objek sasaran. Hasil dari survey mitra dapat memberikan gambaran persoalan yang dihadapi oleh mitra. Kegiatan pengabdian masyarakat dengan skema Program Kemitraan Masyarakat ini dilaksanakan untuk sekolah dasar yang dinaungi oleh UPTD Pendidikan Kecamatan Kuningan di Kabupaten Kuningan Provinsi Jawa Barat. Mitra yang terlibat berkontribusi mengarahkan guru-guru SD yang akan mengikuti pelatihan pembuatan dan pendampingan penerapan multimedia TAVAGIS (Teks, Audio, 
Video, Animasi, Graph, Interacivity, and Spesial Effect) berbasis Prezi dalam pembelajaran Kurikulum 2013.

\section{Lisensi Pelatihan}

Setelah melakukan survei mitra, maka tim pengusul mengajukan kerja sama untuk memberikan solusi dari permasalahan yang muncul pada mitra berupa pelatihan. Jika kerja sama kegiatan Program Kemitraan Masyarakat yang ditawarkan disetujui, maka Kepala UPTD Pendidikan Kecamatan Kuningan menerbitkan surat pernyataan bersedia bermitra dengan Tim Pengusul. Selanjutnya, tim pelaksana mengajukan lisensi kepada Kepala Dinas Pendidikan Kabupaten Kuningan berupa ijin mengadakan pelatihan serta kesediaan menerbitkan sertifikat dengan lisensi Kepala Dinas Pendidikan Kabupaten Kuningan untuk peserta kegiatan.

\section{Penyusunan Modul Pelatihan}

Tim Pelaksana selanjutnya menyusun modul pelatihan berupa buku ber-ISBN, tutorial video, dan slide presentasi untuk memudahkan tim pelaksana yang bertugas sebagai narasumber maupun tutor dalam menyampaikan materi.

\section{Persiapan Pelatihan dan Koordinasi}

Persiapan pelatihan dilakukan oleh tim pelaksana bekerjasama dengan Ketua Kelompok Kerja Kepala Sekolah (K3S) bidang SD di Kecamatan Kuningan, yang sebelumnya telah dihubungkan oleh Kepala UPTD Pendidikan Kecamatan Kuningan kepada tim pelaksana. Pembahasan yang dilakukan dalam persiapan pelatihan adalah lokasi pelatihan, narasumber, tema, susunan acara, dan jadwal pendampingan penerapan.

\section{Sosialisasi Program Pelatihan}

Sosialisasi program bertujuan untuk memberi informasi tentang rencana serangkaian pelaksanaan program dari hari pertama hingga hari terakhir. Sosialisasi disampaikan kepada peserta yang akan mendapat pelatihan sekaligus menyampaikan bahwa hasil pelatihan kemudian akan diterapkan di sekolah masing-masing didampingi oleh tim PKM didampingi tim pengawas UPTD Pendidikan Kecamatan Kuningan.

\section{Pelaksanaan Kegiatan PKM}

\section{Pelatihan Pembuatan Multimedia}

Pelaksanaan program pengabdian kepada masyarakat dengan Program Kemitraan Masyarakat (PKM) adalah berupa workshop atau pelatihan pembuatan multimedia TAVAGIS (Teks, Audio, Video, Animasi, Graph, Interacivity, and Spesial Effect) berbasis Prezi dalam pembelajaran Kurikulum 2013. Pelatihan dilaksanakan sebanyak 4 sesi. Peserta yang dapat hadir dalam pelatihan ini terdiri dari 49 peserta yang merupakan guru kelas IV sekolah dasar se-Kecamatan Kuningan Kabupaten Kuningan. Kegiatan dilaksanakan di Ruang Pertemuan STKIP Muhammadiyah Kuningan yang beralamat di Jalan Moertasiah Soepomo No 28 B Kuningan Jawa Barat.

\section{Pendampingan Penggunaan Multimedia}

Pendampingan penerapan multimedia TAVAGIS (Teks, Audio, Video, Animasi, Graph, Interacivity, and Spesial Effect) berbasis Prezi dalam pembelajaran Kurikulum 2013 yang 
telah dibuat oleh guru di sekolah dilakukan kepada 5 sekolah yang terpilih secara random.

\section{Evaluasi dan Tindak Lanjut}

Kegiatan ini mengevaluasi perkembangan pembuatan dan penerapan multimedia TAVAGIS (Teks, Audio, Video, Animasi, Graph, Interacivity, and Spesial Effect) berbasis Prezi dalam pembelajaran Kurikulum 2013 yang dilaksanakan oleh guru serta memberi masukan-masukan dari keterbatasan pelaksanaan program ini demi perbaikan untuk penerapan pada sekolah dasar lain di Kabupaten Kuningan. Selanjutnya, dilakukan kegiatan tindak lanjut berupa perbaikan-perbaikan terhadap kekurangan yang muncul serta mengembangkan kegiatan untuk tingkat kelas yang lain, yang akan dilakukan oleh UPTD Pendidikan Kecamatan Kuningan dalam Kegiatan Kelompok Kerja Guru (KKG).

\section{HASIL DAN PEMBAHASAN}

\section{Perencanaan Kegiatan}

Kegiatan perencanaan diawali dengan survei mitra yaitu UPTD Pendidikan Kecamatan Kuningan Kabupaten Kuningan. Survey mitra bertujuan untuk menganalisis situasi dan keadaan yang terjadi di lapangan. Berdasarkan hasil survey memberikan gambaran bahwa salah satu permasalahan yang dihadapi mengenai implementasi kurikulum 2013 khususnya tingkat sekolah dasar di Kecamatan Kuningan Kabupaten Kuningan adalah minimnya penguasaan informasi dan teknologi (IT) oleh guru, dikarenakan pola kebiasaan pembelajaran yang masih belum menganggap penting peranan IT dalam meningkatkan kualitas pembelajaran. Padahal guru dituntut untuk menguasai IT di era teknologi ini. Selanjutnya tim pelaksana mengadakan kerja sama dan mengajukan lisensi untuk mengadakan pelatihan pembuatan dan pendampingan penerapan multimedia TAVAGIS (Teks, Audio, Video, Animasi, Graph, Interacivity, and Spesial Effect) berbasis Prezi dalam pembelajaran Kurikulum 2013. Mitra yang terlibat berkontribusi mengarahkan guru-guru SD yang akan mengikuti kegiatan tersebut.

Bertujuan agar peserta dapat lebih mudah memahami cara pembuatan multimedia TAVAGIS berbasis Prezi, maka tim PKM juga menyusun buku dengan judul "Prezi: Multimedia TAVAGIS (Teks, Audio, Video, Animasi, Graph, Interacivity, and Spesial Effect) untuk Kurikulum 2013 Sekolah Dasar". Selain, modul cetak, kami juga membuat CD yang berisi Video Tutorial membuat multimedia TAVAGIS berbasis Prezi, serta slide presentasi mengenai Prezi, yang kemudian seluruh modul baik cetak, video tutorial, maupun slide didistribusikan kepada seluruh peserta pelatihan. Di bawah ini merupakan ulasan isi materi yang terdapat dalam modul cetak.

Bab pertama menjelaskan pendahuluan yang mengulas tentang pentingnya teknologi komputer, informasi, dan komunikasi. Bab kedua menjelaskan Multimedia TAVAGIS yang mengulas tentang pengertian multimedia pembelajaran, manfaat multimedia untuk pembelajaran, fungsi multimedia pembelajaran, pengertian multimedia TAVAGIS beserta komponen-komponennya (Teks, Audio, Video, Animasi, Graph, Interacivity, dan Special Effect). Bab ketiga menjelaskan tentang mengenal Prezi yang mengulas pengertian Prezi, sejarah munculnya Prezi, perbedaan Prezi dan Microsoft Power Point, kelebihan dan kelemahan Prezi, serta manfaat Prezi dalam pembelajaran. 
Bab keempat pada modul mulai membahas tentang cara membuat akun Prezi dengan License Basic. Berikut tampilan utama Prezi dalam http://prezi.com.

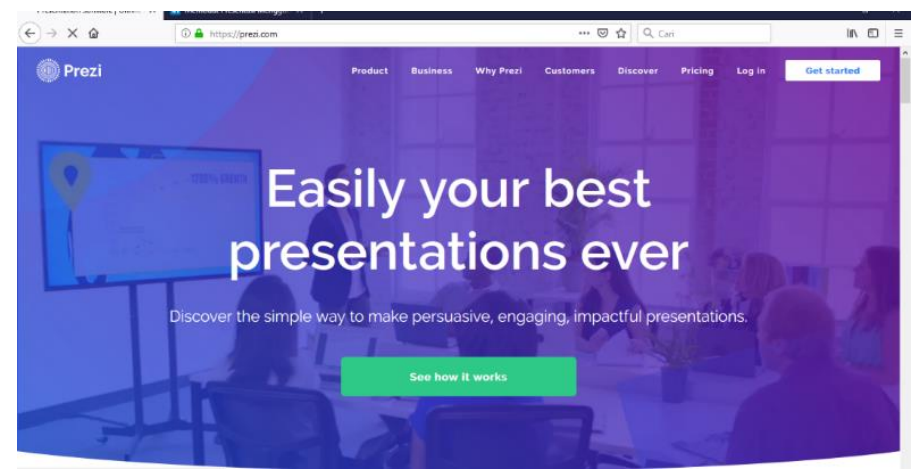

Gambar 1. Tampilan Utama Prezi

Bab kelima pada modul mulai mengajak pembaca untuk mengenal tools dalam Prezi. Berikut merupakan gambar beberapa tools dalam Prezi.

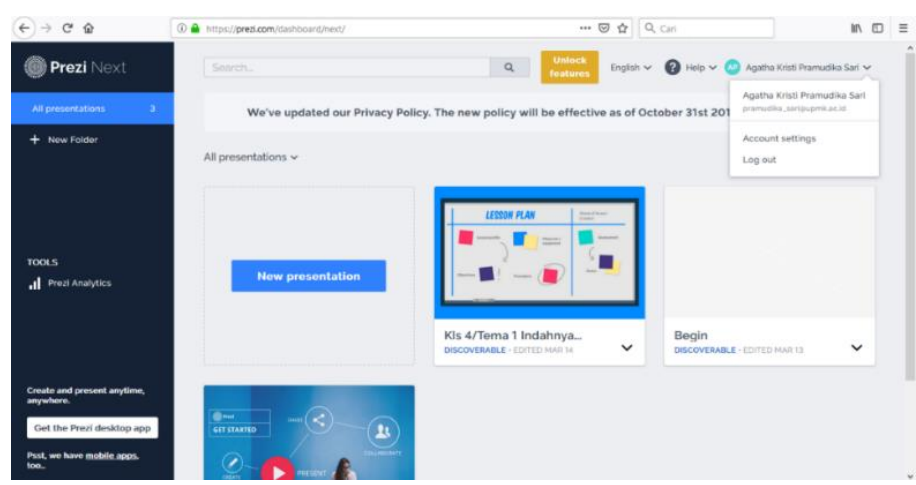

Gambar 2. Tampilan Tools Sesudah Login pada Prezi

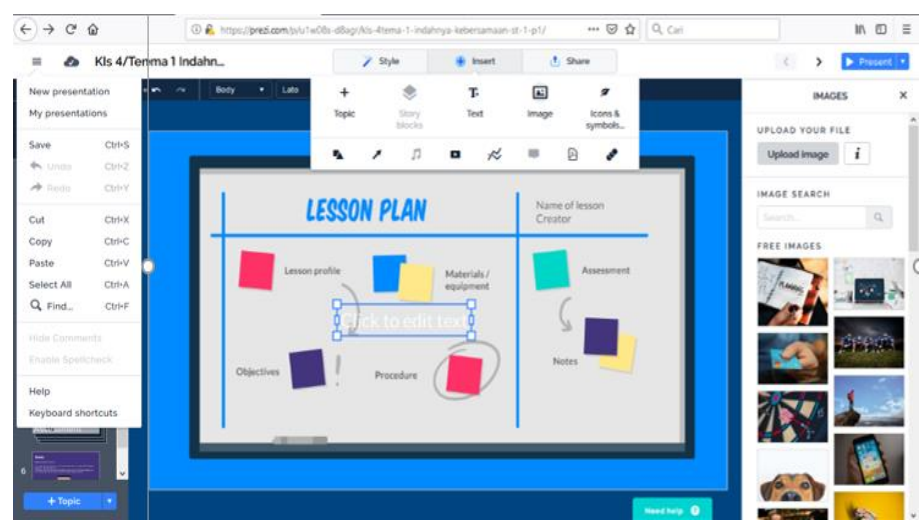

Gambar 3. Tampilan Tools Sesudah Memilih Template

Setelah mengenal tools dalam Prezi, maka pada bab keenam pada modul pembaca akan diajak untuk memulai menggunakan Prezi untuk kurikulum 2013 sekolah dasar. Berawal dari memilih template yang sesuai dengan kurikulum 2013 yaitu yang bertemakan lesson plan dan dilanjutkan dengan membuat presentasi dengan mengisi menu-menu yang terdapat pada template yang dipilih. 
Adapun menu-menu yang terdapat dalam template lesson plan yaitu yang pertama, lesson profile yang dapat diisi pembukaan pembelajaran, setting tempat duduk pada saat pembelajaran, dan kompetensi dasar. Menu kedua adalah objectives yang dapat diisi dengan tujuan pembelajaran secara umum dan khusus. Menu ketiga adalah materials and equipment yang dapat diisi dengan pemaparan materi pembelajaran serta media yang digunakan. Menu keempat adalah procedure yang berfungsi memaparkan langkahlangkah kegiatan sesuai RPP. Menu kelima adalah assesment yang berfungsi untuk penilaian akhir, baik aspek kognitif, afektif, maupun psikomotor. Menu terakhir adalah note yang berfungsi sebagai catatan kecil untuk disampaikan kepada audience.

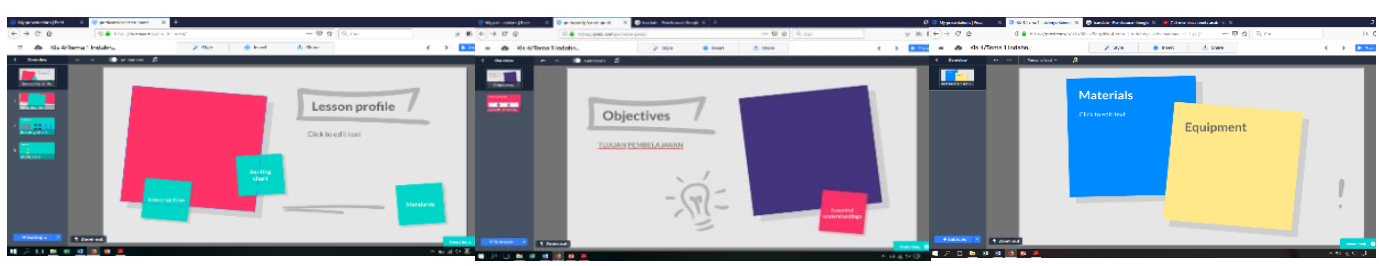

(a)

(b)

(c)

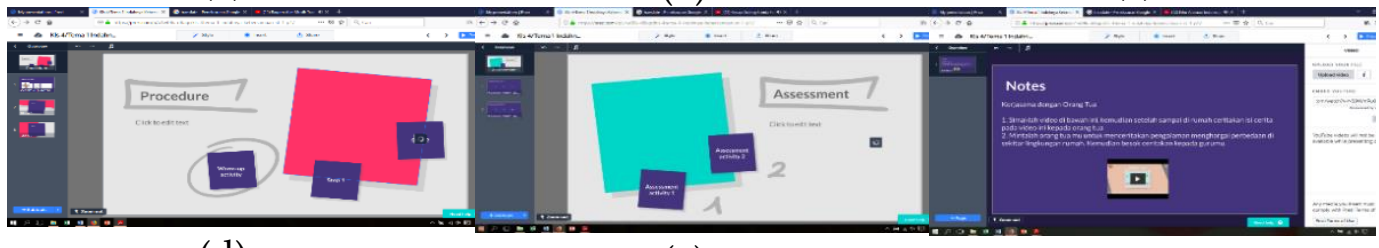

(d)

(e)

(f)

Gambar 4. Tampilan menu pada template lesson plan: (a) lesson profile; (b) objectives; (c) materials and equipment; (d) procedure; (e) assesment; (f) note

Setelah modul cetak, video tutrial, dan kelengkapan modul lainnya selesai disusun, selanjutnya tim pelaksana melakukan persiapan pelatihan dan koordinasi dengan Ketua Kelompok Kerja Kepala Sekolah (K3S) bidang SD di Kecamatan Kuningan. Koordinasi berjalan dengan lancar, mulai dari persiapan lokasi pelatihan, narasumber, tema, materi, susunan acara, dan kelengkapan lainnya. Kegiatan perencanaan diakhiri dengan sosialisasi program pelatihan kepada calon peserta pelatihan, sehingga celon peserta pelatihan mendapat penjelasan teknis sebelum mengikuti pelatihan.

\section{Pelaksanaan PKM}

Pelatihan yang diadakan oleh tim PKM diikuti oleh 49 peserta yang merupakan guru kelas IV sekolah dasar se-Kecamatan Kuningan dan dilakukan sebanyak 4 sesi pada bulan Juli 2019, bertempat di Ruang Pertemuan STKIP Muhammdiyah Kuningan. Adapun kegiatan pada masing-masing sesi adalah sebagai berikut:

Sesi 1, dilakukan pembukaan kegiatan dengan susunan acara doa pembuka, menyanyikan lagu Indonesia Raya dan Mars Muhammadiyah, sambutan Ketua STKIP Muhammadiyah Kuningan, Pembukaan kegiatan oleh Kepala Dinas Pendidikan dan Kebudayaan Kabupaten Kuningan, dan doa penutup. Setelah acara pembukaan kegiatan berlangsung, dilanjutkan dengan penyampaian materi pertama, yaitu "Kebijakan Pendidikan pada Era Revolusi Industri 4.0" oleh Kepala Dinas Pendidikan dan Kebudayaan Kabupaten Kuningan. 


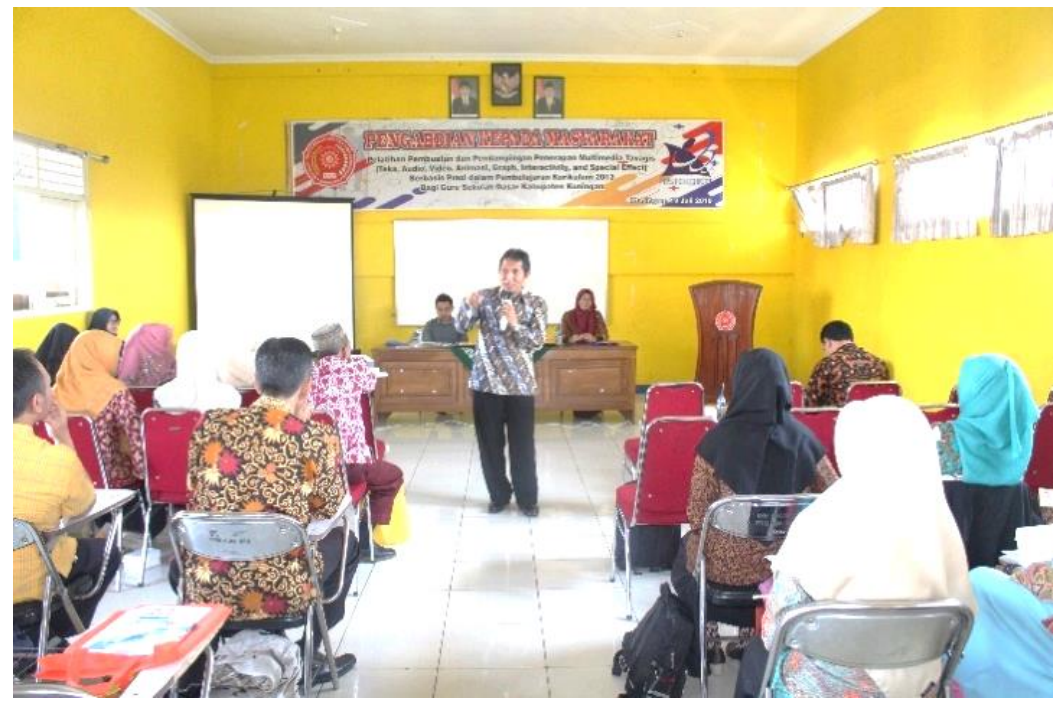

Gambar 5. Kegiatan Pelatihan Sesi 1

Penyampaian materi kedua yaitu "Tantangan Guru di Era Revolusi Industri 4.0" oleh Ketua STKIP Muhammadiyah Kuningan. Penyampaian materi ketiga yaitu "Multimedia TAVAGIS (Text, Audio, Video, Animasi, Graph, Interactivity, and Special Effects)" oleh Ketua Tim PKM. Penyampaian materi keempat yaitu "Prezi" yang didalamnya meliputi mengajak peserta untuk mengenal Prezi, memandu peserta untuk membuat akun Prezi dengan License Basic, dan memandu peserta untuk mengenal tools dalam Prezi. Pelaksanaan kegiatan dapat dilihat pada Gambar 5.

Sesi 2, disampaikan terlebih dahulu video tutorial tentang pembuatan Multimedia TAVAGIS berbasis Prezi untuk Kurikulum 2013 Sekolah Dasar. Peserta dibagikan bahan yang akan dikembangkan menjadi sebuah presentasi menggunakan Prezi. Bahan tersebut diambil dari buku guru dan buku siswa kurikulum 2013 khususnya kelas 4 semester 1 . Peserta diberikan tema, sub tema, pembelajaran secara random. Tim pelaksana PKM menjadi tutor dalam praktek pembuatan Multimedia TAVAGIS berbasis Prezi, juga dibantu oleh beberapa rekan mahasiswa STKIP Muhammadiyah Kuningan yang telah mahir mengoperasikan Prezi.

Sesi 3, dilakukan kegiatan presentasi hasil pembuatan Multimedia TAVAGIS berbasis Prezi oleh peserta pelatihan.

Sesi 4, dilaksanakan kegiatan evaluasi dan tindak lanjut berupa kritik dan saran dari tim tutor untuk peserta pelatihan mengenai hasil pembuatan Multimedia TAVAGIS berbasis Prezi, pengumpulan hasil kerja peserta kepada tutor, pendistribusian hasil multimedia siap pakai kepada seluruh peserta untuk diterapkan di masing-masing sekolah, pengisian angket responden setelah mengikuti pelatihan, serta kritik dan saran peserta pelatihan terhadap pelaksanaan pelatihan. Pada sesi ini juga dilaksanakan kegiatan penutup dengan susunan acara yaitu doa pembuka, laporan ketua pelaksana, pembagian reward kepada peserta terbaik, menutup acara pelatihan oleh Ketua LPKM STKIP Muhamamdiyah Kuningan, dan doa penutup. Pelaksanaan kegiatan dapat dilihat pada Gambar 6. 


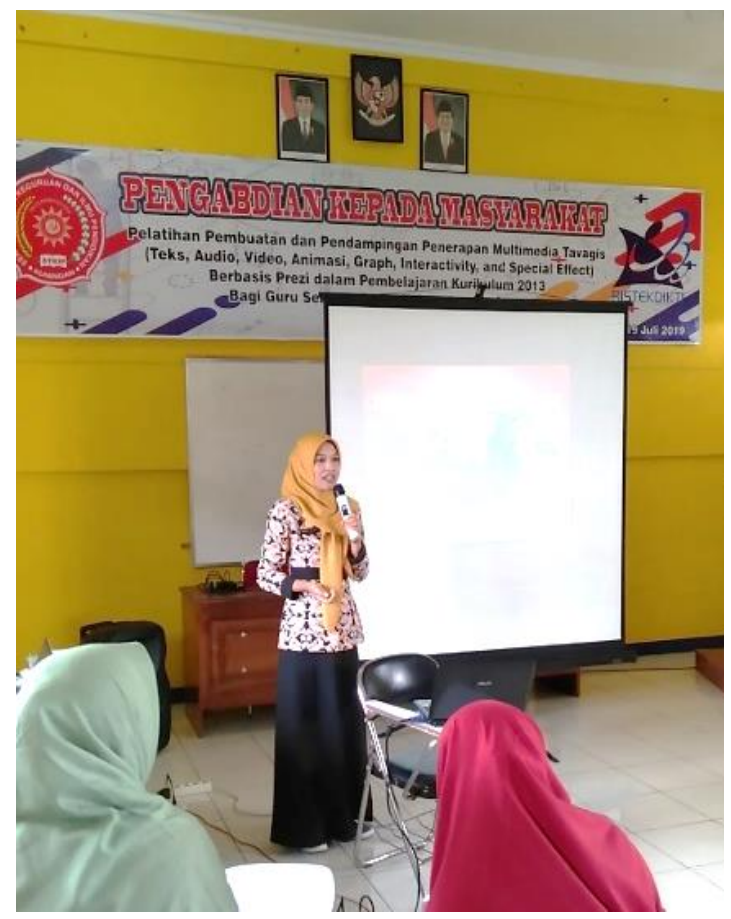

Gambar 6. Peserta Mempresentasikan Hasil Pembuatan Multimedia TAVAGIS

Pendampingan Penerapan Produk, kegiatan pendampingan penerapan Multimedia TAVAGIS (Text, Audio, Video, Animasi, Graph, Interactivity, and Special Effects) Berbasis Prezi dalam Pembelajaran Kurikulum 2013 bagi Guru Sekolah Dasar di Kabupaten Kuningan dilaksanakan pada lima sekolah yang terpilih sebagai sampel. Pendampingan ini dilaksanakan pada bulan Agustus 2019.

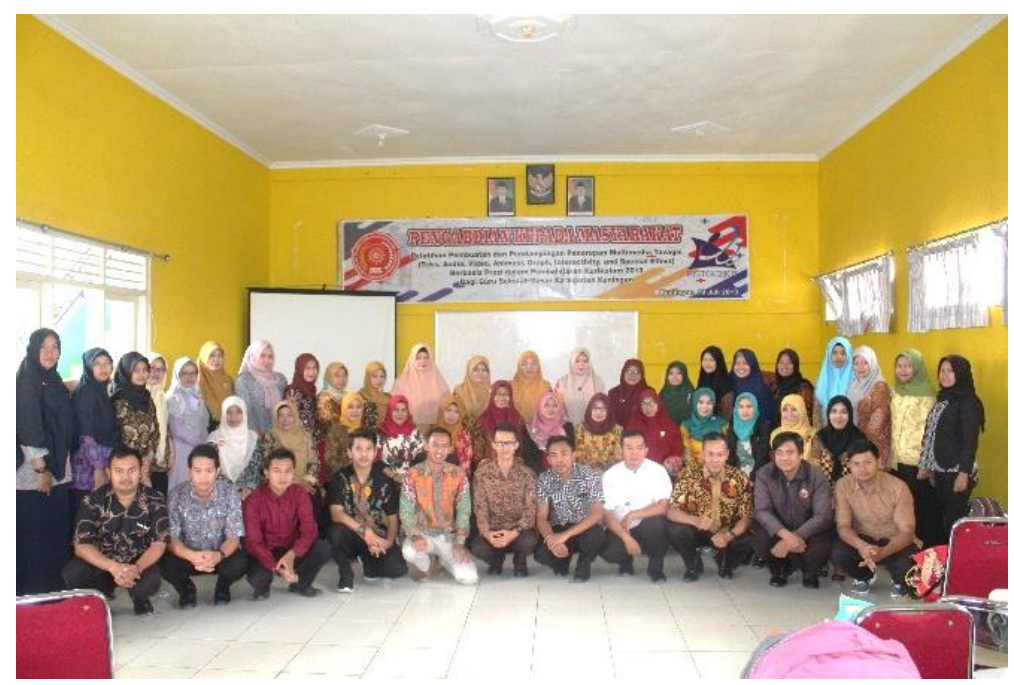

Gambar 7. Kegiatan Foto Bersama

\section{Evaluasi dan Tindak Lanjut}

Evaluasi dilaksanakan pada hari terakhir berupa kritik dan saran dari tim tutor untuk peserta yang telah melaksanakan presentasi hasil, pengumpulan hasil pelatihan 
kepada tutor, dan dialog antara tim pelaksana dan peserta mengenai kritik dan saran terhadap pelaksanaan kegiatan. Selama pelaksanaan kegiatan juga dilakukan observasi dan penyebaran angket kepada responden.

Berdasarkan data observasi, hasil yang dicapai dalam kegiatan Program Kemitraan Masyarakat (PKM) ini adalah sebagai berikut:

Rata-rata skor hasil observasi keterlaksanaan kegiatan yaitu $87,8 \%$ artinya terlaksana dengan baik. Data tersebut berdasarkan rata-rata hasil observasi yang dilakukan oleh 3 observer yaitu Ketua LPKM STKIP Muhammadiyah Kuningan dengan skor 88,3\%, Ketua Pelaksana PKM dengan skor 90\% dan anggota pelaksana PKM dengan skor 85\%,

Berdasarkan hasil observasi yang dilakukan oleh ketiga observer tersebut, terdapat temuan-temuan antara lain jumlah peserta yang hadir sesuai dengan target, peserta pelatihan cepat memahami materi, suasana pelatihan interaktif dan menyenangkan, sarana dan prasarana terpenuhi sesuai yang diharapkan, modul yang dibagikan dapat membantu peserta maupun pelatih dalam kegiatan, pelatihan terlaksana sesuai jadwal yang ditentukan, terjadi interaksi antara peserta dan pelatih, dan materi yang ditargetkan tersampaikan dengan baik.

Berdasarkan hasil observasi ditemui juga beberapa kendala dalam pelaksanaan kegiatan antara lain ada beberapa peserta yang sangat kesulitan untuk mengoperasikan komputer, serta ada beberapa peserta yang belum menyelesaikan produk pelatihan Prezi yang diberikan oleh tutor.

Pengisian angket juga dilakukan oleh 49 peserta sebagai responden. Adapun hasil jawaban angket respon guru tehadap kegiatan adalah sebagai berikut:

Tabel 1. Hasil Jawaban Angket Responden

\begin{tabular}{|c|c|c|c|}
\hline \multirow{2}{*}{ No } & \multirow{2}{*}{ Indikator } & \multicolumn{2}{|c|}{ Hasil Jawaban Responden } \\
\hline & & Skor & Prosentase $(\%)$ \\
\hline 1 & $\begin{array}{l}\text { Antusiasme Mitra terhadap kegiatan pelatihan } \\
\text { dan pendampingan }\end{array}$ & 929 & 94,80 \\
\hline 2 & $\begin{array}{lll}\text { Pengetahuan Mitra } & \text { tentang } & \text { Multimedia } \\
\text { TAVAGIS berbasis Prezi } & & \\
\end{array}$ & 892 & 91,02 \\
\hline 3 & $\begin{array}{l}\text { Pemahaman Mitra terhadap Multimedia } \\
\text { TAVAGIS berbasis Prezi }\end{array}$ & 884 & 90,20 \\
\hline 4 & $\begin{array}{l}\text { Keterampilan Mitra dalam membuat dan } \\
\text { menerapkan Multimedia TAVAGIS berbasis Prezi }\end{array}$ & 856 & 87,35 \\
\hline 5 & Keaktifan Mitra selama Mengikuti Kegiatan & 908 & 92,65 \\
\hline 6 & Partisipasi Mitra selama mengikuti kegiatan & 701 & 95,37 \\
\hline 7 & Perilaku Mitra selama mengikuti kegiatan & 672 & 91,43 \\
\hline 8 & $\begin{array}{l}\text { Kebermanfaatan Multimedia TAVAGIS berbasis } \\
\text { Prezi }\end{array}$ & 935 & 95,41 \\
\hline & Jumlah & 6777 & 92,20 \\
\hline
\end{tabular}

Berdasarkan tabel 1 tersebut dapat disimpulkan bahwa 8 indikator respon guru terhadap Pelatihan Pembuatan dan Pendampingan Penerapan Multimedia TAVAGIS berbasis Prezi untuk Kurikulum 2013 sangat positif. Hal itu ditunjukkan melalui 
prosentase skor keseluruhan pada hasil angket yaitu sebesar 92,20\%, termasuk dalam kategori sangat tinggi. Adapun sisa skor 7,80\% diantaranya dimungkinkan mengalami kendala sesuai dengan hasil observasi.

Tindak lanjut dilakukan oleh tim pelaksana berupa pendistribusian hasil multimedia yang telah dibuat dan siap pakai kepada seluruh peserta untuk diterapkan di masingmasing sekolah, memberikan reward kepada peserta terbaik, serta mengatasi kendalakendala yang terjadi selama kegiatan berlangsung. Solusi untuk mengatasi kendala yang terjadi antara lain dengan mendampingi guru yang kesulitan dalam mengoperasikan komputer oleh tutor pendamping. UPTD Pendidikan Kecamatan Kuningan juga merencanakan akan melanjutkan materi pelatihan ini dalam Kegiatan Kelompok Kerja Guru (KKG) agar Multimedia TAVAGIS dapat dikembangkan dan digunakan pada tingkatan kelas yang lain.

\section{SIMPULAN}

Berdasarkan hasil dan pembahasan, dapat dsimpulkan bahwa kegiatan perencanaan hingga pelaksanaan pelatihan berjalan dengan baik, walaupun setelah dievaluasi terdapat beberapa kendala. Kendala tersebut berhasil diatasi oleh tim pelaksana. Berdasarkan hasil pelatihan, multimedia TAVAGIS berbasis Prezi dapat meningkatkan penguasaan informasi dan teknologi yang dimiliki oleh guru, sehingga membantu guru dalam menciptakan pembelajaran yang interaktif, menarik, menyenangkan, dan mudah diakses oleh peserta didik didampingi oleh orang tua, dimanapun dan kapanpun.

\section{UCAPAN TERIMA KASIH}

Terimakasih kepada DRPM Kemenristekdikti yang memberikan hibah melalui skema Program Kemitraan Masyarakat (PKM), seluruh civitas akademika STKIP Muhammadiyah Kuningan, para pihak yang telah membantu penulisan karya tulis ilmiah ini.

\section{REFERENSI}

Daryanto. (2011). Media pembelajaran. Bandung: Sarana Tutorial Nurani Sejahtera.

Kustiono. (2010). Media pembelajaran konsep, nilai edukatif, klasifikasi, praktek, pemanfaatan dan pengembangan. Semarang: UNNES Press.

Sari, A. K. P., \& Falah, I. F. (2018). Perbedaan stress level siswa sekolah dasar antara fullday dan half-day school di kabupaten Kuningan. Jurnal Ilmiah Educater: Unggul dan Berdaya Saing, 4(2), 142-148.

Rumidjan, Sumanto, S., Sukamti, S., \& Sugiharti, S. (2017). Pelatihan pembuatan media pembelajaran untuk meningkatkan kualitas pembelajaran bagi guru sekolah dasar. Abdimas Pedagogi: Jurnal Ilmiah Pengabdian kepada Masyarakat, 1(1), 71-81.

Rusyfian, Z. (2016). PREZI solusi presentasi masa kini. Bandung: Informatika Bandung. 
Fatmawati, I. (2016). Penerapan model ARIAS dengan media Prezi untuk meningkatkan motivasi belajar siswa di SMK Negeri 3 Salatiga. Salatiga: Universitas Kristen Satya Wacana.

Suryani, S., Khairil, K., \& Nurmaliah, C. (2015). Penggunaan media Prezi pada materi sistem peredaran darah manusia untuk meningkatkan kreativitas peserta didik SMA Negeri 1 Lhoksukon. Jurnal Edubio Tropika, 3(1), 1-5.

Wati, D. P., Sahrir, D. C., \& Lutfi, A. F. (2018). Pelatihan pembuatan dan pendampingan penerapan multimedia genggam Si Dio (Camtasia Studio) berbasis android bagi tutor PKBM di Kabupaten Kuningan. Jurnal Pengabdian Pada Masyarakat, 3(2), 125134. 